\title{
Properties, Application and Synthesis Methods of Nano-Molybdenum Powder
}

\author{
Pengfa Feng, Weicheng Cao \\ Jinduicheng Molybdenum Co., Ltd., Xi'an, China \\ Email: fpf02@sina.com
}

How to cite this paper: Feng, P.F. and Cao, W.C. (2016) Properties, Application and Synthesis Methods of Nano-Molybdenum Powder. Journal of Materials Science and Chemical Engineering, 4, 36-44. http://dx.doi.org/10.4236/msce.2016.49004

Received: August 15, 2016

Accepted: September 24, 2016

Published: September 27, 2016

Copyright $\odot 2016$ by authors and Scientific Research Publishing Inc. This work is licensed under the Creative Commons Attribution International License (CC BY 4.0) http://creativecommons.org/licenses/by/4.0/

\begin{abstract}
Nano molybdenum powder has been applied in many industrial fields in forms of lubricant additives, metallurgical additives, powder sintering additives, and one of raw materials of electrical components, cleaner and smoke suppressor. The processes, mechanisms and prospects of its synthesis methods are comprehensively analysized, including plasma physical vapor deposition technology (PPVD), reduction of $\mathrm{MoCl}_{4}$ vapor, activated reduction technology, electro-explosion of molybdenum wire (Elex process), pulsed wire discharge technology, electron beam irradiating method, hybrid plasma process, vapor phase reduction of $\mathrm{MoO}_{3}$, and microwave plasma chemical vapor deposition (MPCVD), etc.
\end{abstract}

\section{Keywords}

Nano Molybdenum Powder, Properties, Synthesis, Application

\section{General Instructions}

The important microstructural features of metals include a) grain size, distribution, and morphology, b) the nature and morphology of grain boundaries and interphase interfaces, c) the perfection and nature of intragrain defects, d) composition profiles across grains and interfaces, and e) identification of residual trapped species from processing. The structure of the grain boundaries is the same in both nanocrystalline and coarse grained materials. Because of the extremely small dimensions, a large volume fraction of atoms is located at the grain boundaries, which confers that the properties of nanocrystalline materials are very often superior to those of conventional polycrystalline coarse grained materials [1]. Nanocrystalline materials exhibit increased strength/hardness, enhanced diffusivity, improved ductility/toughness, reduced density, reduced elastic modulus, higher electrical resistivity, increased specific heat, higher thermal expan- 
sion coefficient, lower thermal conductivity, and superior soft magnetic properties in comparison with conventional coarse grained materials [1].

Molybdenum and molybdenum-based materials are widely used in chemical engineering, military, energy, electronics, bio-medicine and agriculture, for the properties of high yielding strength and hardness at high temperature, excellent thermal and electrical conductivities, good erosion-resistance, etc. [2]-[4]. Molybdenum-based nanostructured materials have sparked a worldwide interest because of their unique optical, electronic and mechanical properties and potential applications in nano devices and functional materials [4].

Nano molybdenum powder is not only a novel family of nano molybdenum materials, but also the raw material or precursor of molybdenum nanostructured materials. Like other nanosized powders, nanosized molybdenum powder has been recognized to possess more attractive properties than its conventional-sized counterpart. For example, nanoparticles comprising molybdenum containing mutlti-metals offer some surprising and unusual benefits as pigments because they ensure homogeneous lattice level mixing of lements, and they are smaller than the visible wavelengths of light (400 - 700 $\mathrm{nm}$ ), which leads to visible wavelengths interacting in unusual ways with nanoparticles compared to particles with micron scale [5].

In the paper, the extensive investigations in recent years on properties, synthesis methods and greatly potential applications of nano molybdenum powder are summarized.

\section{Intrinsic Properties and Applications}

Like other nanosized powders, nano molybdenum powder possesses intrinsic properties including the quantum size effect (Kubo effect), small size effect, surface effect, and macroscopic quantum tunnelling effect [6]. Therefore, both nano pure molybdenum particles and molybdenum-containing compounds have been broadly used in the fields of magnetic materials, electronic materials, optical materials, high relative density sintering, chemical catalysis, and sensing.

1) Lubricant additives. Nanoscale molybdenum comprising substances, including molybdenum nanoparticles, molybdenum oxides and sulfides, are used for lubricant applications in several industries including automotive and defense. Concentrations of around $0.25 \mathrm{wt} \%$ molybdenum nanopowder may reduce static or dynamic coefficient of friction (COF) between two surfaces by $5 \%$ or more [7] [8]. In certain embodiments such as high precision, tight gap moving surfaces, such lubricating nanoparticles possess the ability to distribute forces more uniformly or lubricate surfaces even at high operating temperatures, and thus may be added to the lubricating fluid, oils, plastic, rubber, coatings, ceramics or powder metal matrices [5].

2) Metallurgical additives. Nanoparticle of molybdenum, including some of its oxides, has enabled development of new alloys that provide improved corrosion and wear resistance. Incorporation of nanoparticles enhances the thermal properties and homogeneity during processing, resulting in superior material properties. The research shows that the addition of $1 \mathrm{wt} \%$ - $4 \mathrm{wt} \%$ nano molybdenum powder can enhance the 
corrosion resistance of stainless steel in corrosion environment [9]. Nano high-purity molybdenum powder prepared by Argonide Corporation is widely used to the products in the aerospace and military fields [10].

3) Electrical applications: Addition of nano molybdenum powder has been shown to improve the properties of electric interconnects. Incorporation of the particles has been shown to enhance the microstructure, mechanical properties, melting characteristics and creep. Nano molybdenum powders are raw materials of heat sink, electronic contact and nano electronic components. For example, the mixture of nano molybdenum powder and $40 \%$ manganese is used in the most common contact of ceramic metal [9]. In Li-ion batteries, the incorporation of molybdenum oxide nanoparticles into porous films has led to profound advancements in state-of-the-art negative electrodes (anodes). Nano-molybdenum is also used in substrates for various photovoltaic cell technologies, including CdTe and organic solar cells.

4) Powder sintering additives. The addition of $3 \mathrm{wt} \%-5 \mathrm{wt} \%$ ultrafine and nano molybdenum powder can help the sintering temperature of the micron-grade molybdenum and ceramic powders greatly decreased, and get the higher density of P/M products [11].

5) Environment. Molybdenum ions have been shown to clean up major pollutant at the surface (aerobic conditions), bottom water (semi aerobic conditions) and the sediments (anaerobic conditions) [11].

6) Smoke suppression. Molybdenum nanoparticle based smoke suppression and fire retardant compositions display longer shelf lives and superior activity [5].

\section{Main Synthesis Procedures}

In the conventional route, micron-scale high-purity molybdenum powder can be produced commercially from either ammonium dimolybdate, $\left(\mathrm{NH}_{4}\right)_{2} \cdot \mathrm{Mo}_{2} \mathrm{O}_{7}(\mathrm{ADM})$ or sublimed $\mathrm{MoO}_{3}$ precursor. The most widely-used conventional processing strategy is comprised of a first-stage and a second-stage flowsheet component, with hydrogen gas employed as the reductant [12]. ADM is processed by an exhaustive chain of pyrometallurgy and hydrometallurgy procedures from molybdenum ore (mainly molybdenite).

Since in 1990, molybdenum nanocrystals ( $4 \mathrm{~nm}<$ particle size $<12 \mathrm{~nm}$ ) were synthesized by Chow et al. [13] in the vapor by sputtering in a thermal gradient at argon pressure between 0.2 and 0.6 Torr, the preparation methods and mechanisms of the ultrafine and the nanometer molybdenum powders have been attracting much attention. In summary, there are two kinds of synthesis routes, i.e. the physical methods (micron grade molybdenum powder as precursor) and the chemical methods (micron or nanometer molybdenum compounds as precursor).

\subsection{Physical Synthesis Procedures}

1) Mechanical ball milling

Whether carbon steel, stainless steel, or carbide alloy are produced to milling balls and container, Sanno Ju et al. [14] [15] have fabricated nano molybdenum powder with particle diameter of about $6 \mathrm{~nm}$ by mechanical ball milling process. However, the solu- 
tion of $\mathrm{Fe}, \mathrm{Cr}, \mathrm{Ni}, \mathrm{W}$ and $\mathrm{Fe}$ in molybdenum, which solution level is several percent, is the most serious problem [16].

2) Plasma physical vapor deposition technology (PPVD)

A precursor comprising of molybdenum powder and gas solvent is fed and sprayed into a high temperature reactor operating at temperature greater than $3000 \mathrm{~K}$ (i.e. DC thermal plasma reactor), wherein the precursor is suspended and inverts into vapor comprising the metal in a process stream with a velocity above 0.25 mach in an in a reductive atmosphere; then the vapor is cooled to nanoscale powders. The powders are then quenched at high gas velocities to prevent agglomeration and growth. The quenched powders are filtered from the gases. The obtained powder has a crystallite size of less than $100 \mathrm{~nm}$ and a specific surface area greater than $10 \mathrm{~m}^{2} / \mathrm{g}$ [5]. Intrinsiq Materials Ltd. has the production capabilities of 1 ton per annual.

3) Electro-explosion of molybdenum wire (Elex process)

In the process, a high power pulse of only a few microseconds duration is applied to a molybdenum wire, which is fed into an argon-filled container. The pulse converts the wire into plasma, which is confined by the extraordinary field created by the high power pulse. The columnar plasma is heated to temperature in excess of 15,000 $\mathrm{K}$ and at these temperatures the resistance soars, causing collapse of the field. The high pressure of the metal vapor causes explosive release, producing a shock wave and rapid adiabatic cooling of the metal aerosols that are produced. The powders formed are unique in their structure compared with evaporation and condensation methods, which produce almost defect free and generally spherical crystals of about $100 \mathrm{~nm}$ in size [17]. Argonide Corporation has been undertaking great efforts to increase the production rate and complement the facility, but still can not meet the requirements of mass production.

4) Pulsed wire discharge technology

The basic principle of the process is illustrated in Figure 1 [18]. A pulsed current is

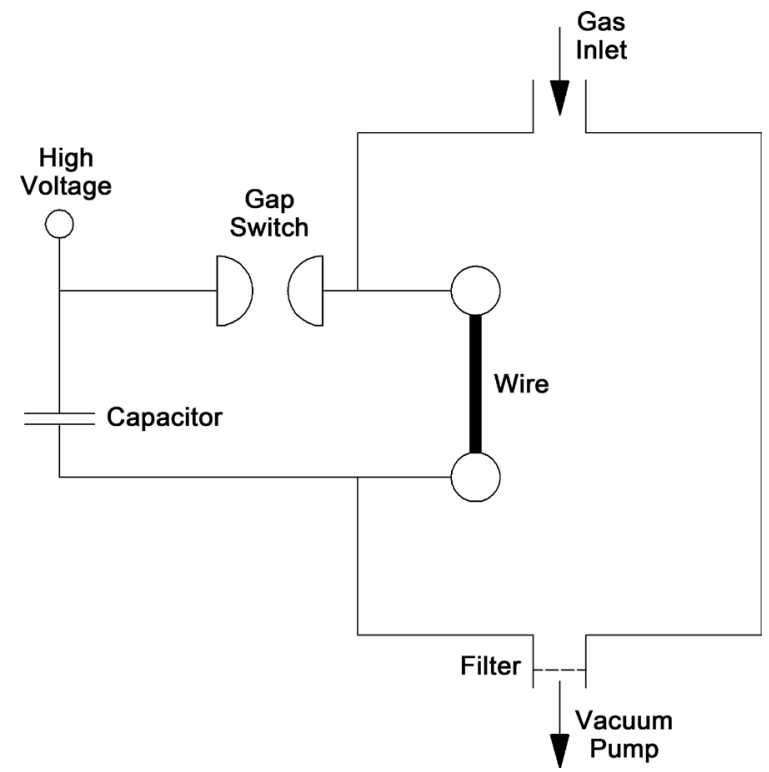

Figure 1. The schematic diagram of pulsed wire discharge technology. 
driven through a molybdenum wire that is located in an ambient gas. The current deposits electrical energy in the wire due to its finite resistance. This deposited energy melts, evaporates, and ionizes the molybdenum wire resulting in a plasma that expands into the ambient gas. This high temperature plasma gradually cools due to its interaction with the gas, giving rise to a high temperature vapor of molybdenum that condenses uniformly in the ambient gas to nano molybdenum powder with the average powder sizes in the range of $20-70 \mathrm{~nm}$. When the discharge is carried out with the peak current of $\sim 10 \mathrm{kA}$, the pulse length of $\sim 20 \mu \mathrm{s}$, and the pulse energy of $\sim 80 \mathrm{~J}$ in argon, the powder production rate of $180 \mathrm{~g} / \mathrm{h}$ is obtained.

Though the basic principle of this process is the same as that of Elex process, the prepared nano molybdenum powder is smaller due to the improvement of the main equipment. This technology is still in the laboratory stage, and the efficiency is very low.

\subsection{Chemical Synthesis Procedures}

1) Activated reduction technology

In the atmosphere of ammonium chloride, Ammonium heptamolybdate

$\left(\left(\mathrm{NH}_{4}\right)_{6} \mathrm{Mo}_{7} \mathrm{O}_{24} \cdot 4 \mathrm{H}_{2} \mathrm{O}, \mathrm{APM}\right)$ is reduced to ultrafine molybdenum powder. The reduction mechanism of the process is as follows:

Ammonium chloride is thermally decomposed: $\mathrm{NH}_{4} \mathrm{Cl}=\mathrm{HCl}+\mathrm{NH}_{3}$

APM is decomposed into molybdenum oxide: $\left(\mathrm{NH}_{4}\right)_{6} \mathrm{Mo}_{7} \mathrm{O}_{24} \cdot 4 \mathrm{H}_{2} \mathrm{O}=6 \mathrm{NH}_{3}+7 \mathrm{MoO}_{3}$ $+7 \mathrm{H}_{2} \mathrm{O}$

The reaction of $\mathrm{MoO}_{3}$ and $\mathrm{HCl}: 7 \mathrm{MoO}_{3}+14 \mathrm{HCl}=7 \mathrm{MoO}_{2} \mathrm{Cl}_{2}+7 \mathrm{H}_{2} \mathrm{O}$

$7 \mathrm{MoO}_{2} \mathrm{Cl}_{2}$ is reduced to ultrafine molybdenum powder by hydrogen: $\mathrm{MoO}_{2} \mathrm{Cl}_{2}+$ $21 \mathrm{H}_{2}=7 \mathrm{Mo}+14 \mathrm{H}_{2} \mathrm{O}+14 \mathrm{HCl}$

The above reaction procedures infer that $\mathrm{NH}_{4} \mathrm{Cl}$ plays a role of catalyst; and that during the reduction process, $\mathrm{NH}_{4} \mathrm{Cl}$ is completely volatized. The total reaction formula is: $\mathrm{NH}_{4} \mathrm{Cl}+\left(\mathrm{NH}_{4}\right)_{6} \mathrm{Mo}_{7} \mathrm{O}_{24} \cdot 4 \mathrm{H}_{2} \mathrm{O}=\mathrm{HCl}+7 \mathrm{NH}_{3}+28 \mathrm{H}_{2} \mathrm{O}+7 \mathrm{Mo}$.

The reduction temperature of the method is lower about 200 - $300 \mathrm{~K}$ [19] compared with the conventional reduction processing, and the processing is only comprised of one reduction stage. The average particle size of the molybdenum powder prepared by this method is $100 \mathrm{~nm}$. The scientists of Five Ridges University in South Korea proposes a similar method with the high-purity $\mathrm{MoO}_{3}$ as raw material.

2) Hybrid plasma process

The high voltage DC arc is sprayed on the high frequency plasma jet by the plasma reaction device, thus forming a mixed plasma gas flow of $\mathrm{H}_{2}$ and $\mathrm{N}_{2}$. Wherein the micron molybdenum oxide particles are reduced to the initial ultrafine molybdenum powders, which are cooled immediately by cooling water into nano molybdenum particles with the average size of about $30-50 \mathrm{~nm}$ and spherical morphologies. The process is applied by NanoProducts Corporation [20]. Due to the high cost of the plasma equipment and low output rate, much attempt will be undertaken for the cheaper production cost.

3) Reduction of $\mathrm{MoCl}_{4}$ vapor

In the process, nano molybdenum powder is prepared by gas phase reaction of $\mathrm{MoCl}_{4^{-}}$ 
$\mathrm{H}_{2}$ mixture [21]. Under $1200^{\circ} \mathrm{C}$, the diameter of molybdenum particle is only 6 - 10 $\mathrm{nm}$. When the temperature is greater than $1200^{\circ} \mathrm{C}$, particles diameter will be increased with increased temperature. Nano molybdenum powder prepared by the method is generally used to produce solder, Monel alloy, solder flux and molybdenum alloy etc.

4) Vapor phase reduction of $\mathrm{MoO}_{3}$

The apparatus used for the powder synthesis is shown in Figure 2 [22]. The reaction tube is made of $\alpha$-alumina. High-purity $\mathrm{MoO}_{3}$ powder contained in a molybdenum boat is placed and vapored between the pre-heating furnace and the main furnace $1300^{\circ} \mathrm{C}-1500^{\circ} \mathrm{C} . \mathrm{MoO}_{3}$ vapor is then carried into the reaction zone and deoxidized into nano molybdenum powder using a stream of nitrogen, which is mixed with a stream of an $\mathrm{H}_{2}-\mathrm{N}_{2}$ gas mixture. As-synthesized nano molybdenum powder is trapped in flasks or by a Microtex-F filter. Molybdenum powder consisting of uniform, spherical particles $40-70 \mathrm{~nm}$ in diameter is obtained by the process. In the process, the parameters are difficultly controlled, in particular the mixing temperature of the $\mathrm{MoO}_{3}-\mathrm{N}_{2}$ and $\mathrm{H}_{2}-\mathrm{N}_{2}$ streams have a significant effect on the particle size.

5) Microwave plasma chemical vapor deposition (MPCVD)

The microwave plasma chemical vapor deposition (MPCVD) method is a novel chemical synthesis technology of nano molybdenum powder [3]. The MPCVD system for the synthesis of Mo powder is illustrated in Figure 3 [23]. During the synthesis of Mo powder, $\mathrm{N}_{2}$ gas with purity of $99.999 \%$ is used as both carrier gas and plasma forming gas. The raw material, $\mathrm{Mo}(\mathrm{CO})_{6}$ powder, is first input in a specially designed feeding equipment (2), and then injected uniformly into the reactor chamber (5) through a reactant injector (4) by the carrier gas at a certain flow rate. In the plasma torch formed in the reactor (5), $\mathrm{Mo}(\mathrm{CO})_{6}$ is thermally decomposed. The products were condensed in the heat exchanger cooled by circular cooling water, separated from the gas by the filter (7), and then collected in the powder collector (8). The mean particle size of the obtained powder was estimated smaller than $50 \mathrm{~nm}$.

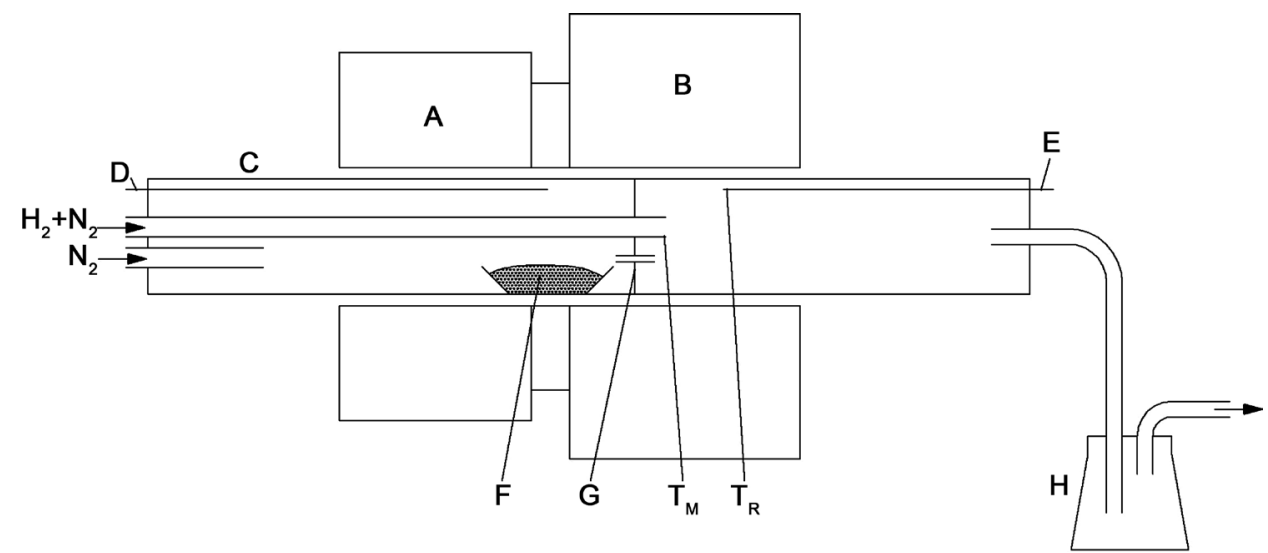

A, pre-heating furnace; $\mathrm{B}$, main furnace; $\mathrm{C}$, reaction tube; $\mathrm{D}$, chromel-alumei thermocouple; $\mathrm{E}$, Pt-Rh thermocouple; F, molybdenum boat; $\mathrm{G}$, molybdenum plate and nozzle; $\mathrm{H}$, fiask

Figure 2. Apparatus for powder synthesis. 


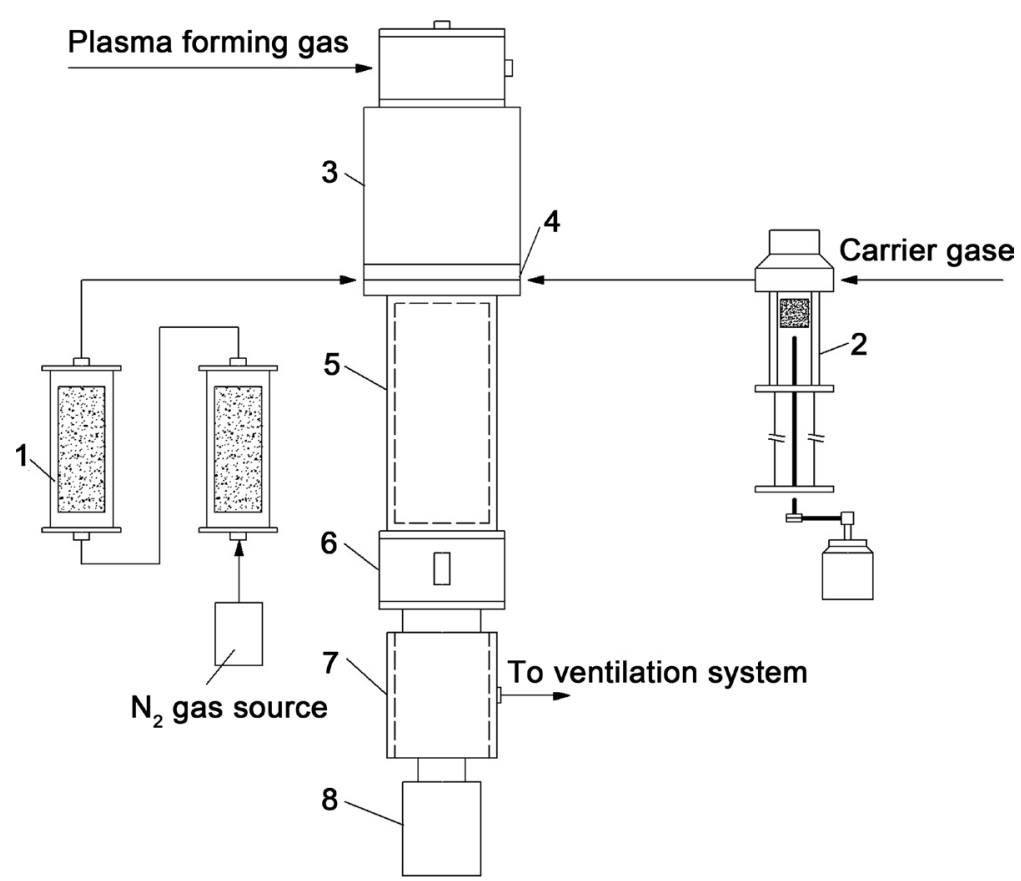

1-Gas purifying system; 2-Feeding equipment; 3-Plasmatron; 4-Reactant rejector; 5-Reactor chamber; 6-Heat exchanger; 7-Filter; 8-Powder collector

Figure 3. Schematic drawing of the MPCVD system for synthesizing Mo powder.

6) Electron beam irradiating method

Heated in HRTEM on a room temperature table by electron beam irradiating of more than $10^{21} \mathrm{e} / \mathrm{cm}^{2} \cdot \mathrm{s}$, micron-sized $\mathrm{MoO}_{3}$ particles are turned into $\mathrm{MoO}_{3-\mathrm{x}}$. With irradiating time prolonged, Mo nanoparticles are formed from $\mathrm{MoO}_{3-\mathrm{x}}$. Wei et al. [24] propose that oxygen atoms in $\mathrm{MoO}_{3}$ micron particles are separated by means of electron beam energy activation, then the micron molybdenum particles are broken into nanoparticles by electron beam "hammer". The diameter of molybdenum nanoparticles were measured $2-20 \mathrm{~nm}$.

\section{Conclusions}

1) Nano molybdenum powder has been broadly applied as lubricant additives, metallurgical additives, powder sintering additives, and one of raw materials of electrical components, cleaner and smoke suppressor.

2) Of the synthesis methods, the plasma physical vapor deposition technology (PPVD), reduction of $\mathrm{MoCl}_{4}$ vapor, activated reduction technology, have applied in the industrial production; electro-explosion of molybdenum wire (Elex process), pulsed wire discharge technology, electron beam irradiating method, are still in the laboratory stage; hybrid plasma process, vapor phase reduction of $\mathrm{MoO}_{3}$, microwave plasma chemical vapor deposition (MPCVD), is of exciting promise of application.

\section{References}

[1] Suryanarayana, C. (1995) Nanocrystalline Materials. International Materials Reviews, 40, 
41-64. http://dx.doi.org/10.1179/imr.1995.40.2.41

[2] Endo, M., Kimura, K., Udagawa, T., Tanabe S. and Seto, H. (1990) The Effects of Doping Molybdenum Wire with Rare-Earth Elements. High Temperature-High Pressures, 21, 129137.

[3] Liu, B.H., Gu, H.C. and Chen, Q.L. (1999) Preparation of Nanosized Mo Powder by Microwave Plasma Chemical Vapor Deposition Method. Materials Chemistry and Physics, 59, 204-209. http://dx.doi.org/10.1016/S0254-0584(99)00007-3

[4] Kong, Y.M. (2006) Synthesis, Characterization and Study on Fuctional Property for Molybdenum-Based Nanomaterials. Ph.D Dissertation, Northeast Normal University, Changchun.

[5] Yadav, T. (2006) Molybdenum Comprising Nanomaterials and Related Nanotechnology. US Patent 20060079410A1.

[6] Ashby, M.F., Ferreira, P.J. and Schodek, D.L. (2010) Nanomaterials, Nanotechnologies and Design. Science Press, Beijing.

[7] Kotnarowski, A. (2006) Triboiogical Properties of Oils Modified with the Addition of Metal Nanoparticles. Solid State Phenomena, 113, 393-398. http://dx.doi.org/10.4028/www.scientific.net/SSP.113.393

[8] Kotnarowski, A. (2010) Antiwear Properties of Lubricants Modified with Metal Particles. Tribologia, 232, 191-200.

[9] http://www.vooec.com/cpshow_2157984/

[10] http://www.argonide.com/nanoceram/

[11] http://intrinsiqmaterials.com/

[12] Martins, G.P., Kangsadan, T., Scott, G., Wanger, C. and Hoose, J.V. (2007) A 21st Century Perspective on Molybdenum Powder Production by Hydrogen Reduction. Materials Science Forum, 561-565, 447-452. http://dx.doi.org/10.4028/www.scientific.net/MSF.561-565.447

[13] Chow, G.M. (1991) Sputtering Synthesis and Properties of Molybdenum Manocrystals and Al/Mo Layer. Journal of Material Research, 4, 737-743. http://dx.doi.org/10.1557/JMR.1991.0737

[14] Torre, S.D.D.L., Oleszak, D., Kakitsuji, A., Miyamoto, K., Miyamoto, H., Martinez-S, R., Almeraya-C, F., Martinez-V, A. and Rios-J, D. (2000) Nickel-Molybdenum Catalysts Fabricated by Mechanical Alloying and Spark Plasma Sintering. Materials Science Engineering $A$, 276, 226-235. http://dx.doi.org/10.1016/S0921-5093(99)00156-2

[15] Sanno, J. (1995) Manufacture of Nano Molybdenum Powder by Ball Milling. Tungsten and Molybdenum Materials, 3, 7-10.

[16] Mechanochemical Processing Route Promises Cheaper Nanopowders (1996) Metal Powder Report, 51, 5 .

[17] Tepper, F. (1998) Electro-Explosion of Wire Produces Nanosize Metals. Metal Powder Report, 53, 31-33. http://dx.doi.org/10.1016/S0026-0657(98)80193-8

[18] Jiang, W.H. and Yatsui, K. (1998) Pulsed Wire Discharge for Nanosize Powder Synthesis. IEEE Transactions on Plasma Science, 26, 1498-1501. http://dx.doi.org/10.1109/27.736045

[19] Yang, B. and Zhong, P.Q. (1994) Preparation of Ultrafine Molybdenum Powder by Activated Reduction Method. Tungsten and Molybdenum Materials, 30-32.

[20] Futaki, S., Shiraishi, K. and Uemura, M. (1992) Ultrafine Refractory Metal Particles Produced by Hybrid Plasma Process. Journal of the Japan Institute of Metals, 56, 464-471.

[21] Ling, X.Q., He, Y.H., Wang, Z.W. and Xiong, J. (2003) Production Technology of Molyb- 
denum Powder and Its Development. Powder Metallurgy Materials Science and Engineering, 8, 128-133.

[22] Shibata, K., Tsuchida, K. and Kato, A. (1990) Preparation of Ultrafine Molybdenum Powder by Vapour Phase Reaction of the $\mathrm{MoO}_{3}-\mathrm{H}_{2}$ System. Journal of the Less-common Metals, 157, L5-L10. http://dx.doi.org/10.1016/0022-5088(90)90420-o

[23] Cheng, Q.L., Zhao, B., Liu, B.H. and Zhang, Z.T. (1998) Preparation of Nano-Mo Powder by Microwave Plasma. Journal of East China University of Science and Technology, 24, 731-734, 740 .

[24] Wei, Y.H., Lu, L., Xu, B.S. and Tanaka, S.I. (2000) Formation of Mo Nanoparticles under Electron Beam Irradiation. Material Science \& Technology, 8, 44-46.

Submit or recommend next manuscript to SCIRP and we will provide best service for you:

Accepting pre-submission inquiries through Email, Facebook, LinkedIn, Twitter, etc. A wide selection of journals (inclusive of 9 subjects, more than 200 journals)

Providing 24-hour high-quality service

User-friendly online submission system

Fair and swift peer-review system

Efficient typesetting and proofreading procedure

Display of the result of downloads and visits, as well as the number of cited articles Maximum dissemination of your research work

Submit your manuscript at: http://papersubmission.scirp.org/

Or contact msce@scirp.org 